\title{
Liberalization of Mexican Electricity Market. Various Modeling Approaches with Numerical Simulation Results
}

\author{
Vitaliy V. Kalashnikov \\ UANL, Facultad de Economía \\ Monterrey, Mexico \\ E-mail: kalashnikov de@yahoo.de
}

\author{
Nataliya Kalashnykova \\ UANL, FCFM \\ Monterrey , México, \\ E-mail: nkalash@fcfm.uanl.mx
}

\begin{abstract}
In this paper we investigate the Mexican real estate market, especially the economy class homes. This sector plays an important role for Mexican social stability. We investigate the Cournot and Stackelberg mixed duopoly models where a stateowned public firm maximizing domestic social surplus, and a foreign firm searching to maximize its own profit, compete.
\end{abstract}

Keywords: mixed oligopoly, market equilibrium

\section{INTRODUCTION}

The crediting system has a crucial role for the society in Mexico due to many reasons. Some of them are: the deficit of the apartments in the renting market (at present, around 6 millions of new homes/apartments are necessary to satisfy naturally existed demand).

Next, the problem of poverty is still very important to Mexico, as around $50 \%$ of it population have monthly incomes below 3000-4000 pesos. Being quite a vulnerable part of the society they are strongly dependent on the state-owned projects of the construction and financing the real estate.

One of the most important one is INFONAVIT. Every officially working citizen has a saving account, to where the part of paid tax is being transferred. And when the person wants to buy a real estate, he can use this money and he will obtain the credit line for the rest of the home's value.

As well, the organization giving the credit obtains governmental guaranties in case of a default.

The computational game theoretic modeling tool for model runs offered in this paper is composed as a mixed complementarity problem (MCP).

Numerical experiments are programmed in computing language GAMS.

At the present time, the mortgage system (both private and public sectors) is offering changing and fixed interest rates. Fixed rates are around $9-11 \%$ and special rates are about $4-6 \%$, but being calculated on the base of minimal salaries. Which mean, the relation of the minimal wage increments to a real inflation rate in Mexico is crucial.

Indeed, if the salary increased less then actual inflation rate, the credit giving bank counts a loss in real money value. Otherwise, if the minimum salaries grow faster then the inflation, the bank counts an increase of the actual credit value.

During last years, we have an increase of the minimal salary stronger then annual inflation rate.

So, even presented as being lower, the special rates, where the risk of inflation covered by credit payer (the debt is counted in minimal salaries) in real terms does not differ from fixed rates.

\section{Formulation OF THE MOdEL AND COURNOT-NASH EQUILIBRIUM.}

The interest in mixed oligopolies is high because of their importance in economies worldwide (see [3]) for analysis of "herd behavior" by private firms in many branches of the economy in Japan.

There are examples of mixed oligopolies in United States such as the packaging and overnight-delivery industries. Mixed oligopolies are also common in the East European and former Soviet Union transitional economies, in which competition among public and private firms existed or still exists in many industries such as banking, house loan, airline, telecommunication, natural gas, electric power, hospital, health care, railways and others.

The A mathematically extended version of applied model is introduced by Kalashnikov et al. [7].

Consider two firms producing a homogeneous product. Let represent the total $\mathbf{G}$ credit output, and $\boldsymbol{p}(\boldsymbol{G})$ denote an inverse demand function, i.e. the interest rate consumer has to pay. The electricity produced by the two firms is sold at the domestic market. In this paper, we will not consider international trade. 
Let $\boldsymbol{q}_{\boldsymbol{i}, \boldsymbol{t}} \mathrm{i}=1,2, \mathrm{t}=1, \ldots, \mathrm{n}$, denote the output of firm using the capital source $t$.

Without affecting generality, we assume both private and public firms have same list of sources. At last, let $\boldsymbol{C}_{\boldsymbol{i}, \boldsymbol{t}}\left(\boldsymbol{q}_{\boldsymbol{i}, \boldsymbol{t}}\right)$ stand for the production cost by firm for the technology $t$. As is the total output, one has

$$
G=\sum_{t=1}^{n}\left(q_{1, t}+q_{2, t}\right)
$$

Firm 1 is a foreign private firm, which maximizes its own profits, and firm 2 is a domestic public firm that maximizes domestic social surplus. Domestic social surplus is the sum of consumer surplus and profits of firm 2, and is given by:

$$
\begin{aligned}
& S q_{2}=\int_{0}^{G} p \underset{n}{x} d x- \\
& \sum_{t=1}^{n}\left[p \underset{q_{1}, t}{G}+q_{2, t}\right]
\end{aligned}
$$

here, of course

$$
q_{2}=\sum_{t=1}^{n} q_{2, t}, q_{1}=\sum_{t=1}^{n} q_{1, t}, q_{1}=G-q_{2}
$$

The profit of firm 1 is given by:

$$
\Pi\left(G, q_{1}\right)=p(G) q_{1, t}-\sum_{t=1}^{n} c_{1, t}\left(q_{1, t}\right)
$$

Now we are in a position to define kinds of equilibrium states and compare the equilibrium volumes for various scenarios. First we consider the classical Cournot equilibrium, i.e., a vector

$$
Z=\left(G, q_{1,1}, \ldots, q_{1, n}, q_{2,1}, \ldots, q_{2, n}\right) \in R_{+}^{2 n+1}
$$

such that:

$$
\begin{aligned}
& \mathbf{G}=\sum_{t=1}^{n} \sum_{i=1}^{2} \boldsymbol{q}_{i, t} \\
& q_{1, t} \geq \cap \varphi_{1, t} \equiv c_{1, t}^{\prime} q_{1, t}-q_{1, t} p^{\prime} G_{-}-p G . \\
& \geq_{\mathbf{0}, \boldsymbol{q}_{1, \mathrm{t}}} \varphi_{1, \mathrm{t}}=0 \forall \boldsymbol{t} \\
& q_{2, t} \geq \cap \varphi_{2, t} \equiv c_{2, t}^{\prime} q_{2, t}+G-q_{2, t} p^{\prime} G \text {. } \\
& -p \underline{G} \geq 0, q_{2, t} \varphi_{2, t}=0, \forall t
\end{aligned}
$$

Problem (4)-(6) is a standard complementarity problem.Therefore, applying analogous methods as in Kalashnikov et al. [7], we obtain the existence and the uniqueness of the equilibrium.

\section{Stackelberg Model With Leadership of Domestic (PUBLIC) FIRM}

First, in this Section, we examine the game where firm 2 (public one) is the leader. Firm 2 chooses its output volume, and firm 1 (private one) chooses after having observed, so as to maximize its net profit

$$
\begin{gathered}
\Pi\left(G, q_{1}\right)=p(G) q_{1}-\sum_{t=1}^{n} c_{1, t}\left(q_{1, t}\right) \\
q_{2}=\sum_{t=1}^{n} q_{2, t}, q_{1}=\sum_{t=1}^{n} q_{1, t}, q_{1}=G-q_{2} \\
\text { where } q_{2}=\sum_{t=1}^{n} q_{2, t}, q_{1}=\sum_{t=1}^{n} q_{1, t}, q_{1}=\mathbf{G}-q_{2}
\end{gathered}
$$

Let $\boldsymbol{q}_{\mathbf{1}}=\boldsymbol{q}_{\mathbf{1}}\left(\boldsymbol{q}_{\mathbf{2}}\right) \geq \mathbf{0}$ be the (optimal) reaction function of firm 1; that is, the value that satisfies the equality:

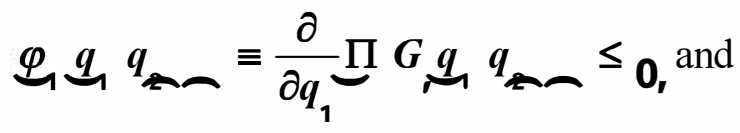

$$
\begin{aligned}
& \varphi_{1} q_{1} q_{A} \cdot q_{1} q_{A}=0
\end{aligned}
$$


Now we are in a position to recall a mathematically rigorous definition of the Stackelberg equilibrium state with the domestic leader and foreign follower.

Definition 1: A Stackelberg equilibrium (with the domestic firm as a leader and the foreign firm as a follower) is the vector $Z=\left(G, q_{1,1}, \ldots, q_{1, n}, q_{2,1}, \ldots, q_{2, n}\right) \in R_{+}^{2 n+1}$ such that

$$
G^{F, L}=\sum_{t=1}^{n}\left\{q_{1, t}^{F}\left(Q^{L}\right)\right\}+Q^{L}
$$

$$
Q^{L} \in \operatorname{Arg} \max \left\{S_{1}(Q) \mid Q \geq 0\right\}
$$

$$
q_{1}^{F}\left(Q^{L}\right)=\arg \max \left\{\Pi\left(G^{F, L}, q_{1}\right) \mid q_{1} \geq 0\right\}
$$

where $Q^{L}=\sum_{t=1}^{n} \boldsymbol{q}_{2, t}^{L}$ - total output of the domestic company and $q_{1}^{F}=\sum_{t=1}^{n} q_{1, t}^{F}\left(Q^{L}\right)$ - optimal response of the private firm. The following three relationships

$$
\begin{aligned}
& G=Q^{L}+q_{1}^{F} \\
& \boldsymbol{q}_{1, t}^{F} \geq \mathbf{0}, \psi_{1, t} \equiv c_{1, t}^{\prime}\left(q_{1, t}^{F}\right)-q_{1, t}^{F} p^{\prime}(G) \\
& -p(G) \geq 0, q_{1, t}^{F} \psi_{1, \mathrm{t}}=\mathbf{0} \forall \boldsymbol{t} \\
& q_{2, t}^{L} \geq \cap \psi_{2, t} \equiv c_{2, t}^{\prime} q_{2, t}^{L}+G-q_{2, t, t}^{L}, p^{\prime} G_{.} \\
& -p \underline{G} \geq 0, q_{2, t} \psi_{2, t}=0, \forall t
\end{aligned}
$$

define a complementarity problem, analogous to the one discussed in Kalashnikov et al. [7].

\section{Stackelberg Model With LeAdership of Foreign}

(Private) Firm

Now consider the game where firm 1 (foreign private firm) is a leader. Firm 1 chooses it $\boldsymbol{q}_{\mathbf{1 , t}}, \boldsymbol{t}=\mathbf{1}, \ldots, \boldsymbol{n}$ and firm 2 (domestic or public supplier) chooses $\boldsymbol{q}_{2, t}, \boldsymbol{t}=\mathbf{1}, \ldots, n$ after having observed $\boldsymbol{q}_{\mathbf{1}, \boldsymbol{t}}, \boldsymbol{t}=\mathbf{1}, \ldots, \boldsymbol{n}$, so as to maximize domestic social surplus

$$
\begin{aligned}
& \underset{S}{G}, q_{\Omega}=\int_{0}^{G} p \underline{x} d x- \\
& \sum_{t=1}^{n}\left[p g_{1, t}+c_{q_{1}} q_{2, t}\right] \\
& \text { Where } q_{2}=\sum_{t=1}^{n} q_{2, t}, q_{1}=\sum_{t=1}^{n} q_{1, t}, q_{1}=G-q_{2}
\end{aligned}
$$

Definition 2: A Stackelberg equilibrium (with the foreign firm as a leader and the domestic firm as a follower) is the vector $Z=\left(G^{L, F}, Q_{1}^{L}, q_{2,1}^{F}\left(Q_{1}^{L}\right), \ldots, q_{2, n}^{F}\left(Q_{1}^{L}\right)\right) \in R_{+}^{n+2}$ such that

$$
\begin{aligned}
& G^{L, F}=Q_{1}^{L}+q_{2}^{F}\left(Q_{1}^{L}\right) \\
& Q_{1}^{L} \in \operatorname{Arg} \max \left\{\Pi_{1}\left(Q_{1}\right) Q_{1} \geq 0\right\} \\
& q_{2}^{F}\left(Q^{L}\right)=\arg \max \left\{S\left(G^{L, F}, q_{2}\right) q_{2} \geq 0\right\}
\end{aligned}
$$

where $Q^{L}=\sum_{t=1}^{n} \boldsymbol{q}_{1, t}^{L}-$ total output of the private firm and

$$
\boldsymbol{q}_{2}^{F}=\sum_{t=1}^{n} \boldsymbol{q}_{2, t}^{F}\left(Q^{L}\right) \text { - optimal response of the domestic }
$$
company. Following three sentences

$G=Q^{L}+q_{2}^{F}$

$q_{1, t}^{L} \geq n \quad \phi_{1, t} \equiv c_{1, t}^{\prime} q_{1, t,}^{L}-q_{1, t}^{L} p^{\prime} . G$.

$-p \underline{G} \geq_{0,}, q_{1, t}^{F} \phi_{1, t}=0 \forall t$

$\boldsymbol{q}_{2, t}^{F} \geq_{0,} \phi_{2, t} \equiv c_{2,}^{\prime} q_{2,+}^{F} \pm G-q_{2, t}^{F}, p^{\prime} G$.

$-p \underline{G} \geq 0, q_{2, t}^{F} \phi_{2, t}=0, \forall t$

define a complementarity problem, analogous with one discussed in [7].

\section{RESULTS AND CONCLUSIONS}

In the above analysis, we investigated three different types of equilibrium in the duopoly with a private (foreign) agent aiming at maximization of its own profit, and a domestic firm maximizing domestic social surplus. After presenting the 
Cournot equilibrium in the above-described model, we examined two versions of Stackelberg game, with the private firm as a leader and domestic one as a follower, and vice versa.

In order to compare the equilibrium volumes in various scenarios we introduce the concepts of a weak and a strong firm, in dependence on the sign of the agent's optimal reaction function's derivative at the Cournot equilibrium. With such a characteristic, it turns out that if the inverse demand function is convex, then the state owned market agent is always weak, and vice versa: if the inverse demand function is concave, then the domestic agent is always strong.

For the Stackelberg equilibrium with the public owned agent as a leader, we obtain that the production volume by the leader (and hence, the total cleared market volume) is higher than that in the Cournot equilibrium, if the private firm (the follower) is strong. Otherwise, if the private agent is weak, then the total cleared market volume is lower with the domestic producer as a leader than that would be in the Cournot equilibrium Kalashnikov et al. [7].

Next, if the foreign (private) firm is a leader, then the relations between the leader's (and hence, the total) offered credit volumes directly depend upon the strength of the state owned credit institution as a follower: if the domestic firm is weak, then the leader's credit volume is higher than that would be in the Cournot equilibrium; otherwise, when the domestic firm is strong, the private leader's output (and hence the total cleared market volume) is lower than that in the Cournot equilibrium Kalashnikov et al. [7].

We have run numerical experiments for the classical Cournot-Nash model and the mixed Cournot-Nash one with a socially-oriented agent. For the inverse demand function, we have chosen the function of form (23) where we have assumed the market elasticity parameter to be equal to 0.9 .
The socially-oriented model offers the credit rates under the existing rates - around $6.7 \%$, which means that we should claim for more social responsibility on the part our state-owned mortgage funds.

The classical model yields the equilibrium rate equal to $9.3 \%$, which is somewhat lower than the actually offered rates.

This difference can be explained by our underestimation of non-payment risks, which is a goal of the further analysis, as well as numerical calculations for Stackelberg model.

\section{ACKNOWLEDGMENT}

This research was supported by the Mexico National Counsel on Science and Technology (CONACyT) within the project SEP-2011 Ciencia Básica Nr. 169765; PROMEP 103.5/11/4330; PAICYT 464-10.

\section{REFERENCES}

[1] Bös, D. (1986). Public Enterprise Economics. North-Holland:

[2] DeFraja, G., and Delbono, F. (1990). Game theoretic models of mixed oligopoly. Journal of Economic Surveys, 4, pp. 1 - 17

[3] Matsumura, T. (2003). Stackelberg mixed duopoly with a foreign competitor. Bulletin of Economic Research, 55, pp. 275 - 287.

[4] Merril, W., and Schneider, N. (1966). Government firms in oligopoly industries: A short-run analysis. Quarterly Journal of Economics, 80, pp. $400-412$.

[5] Nett, L. (1993). Mixed oligopoly with homogeneous goods. Annals of Public and Cooperative Economics, 64, pp. 367 - 393.

[6] G. Isac, V. A. Bulavsky and V. V. Kalashnikov, (2002). Complementarity, Equilibrium, Efficiency and Economics. Kluwer Academic Publishers: Dordrecht/ Boston/ London. - 468 p.

[7] Vyacheslav Kalashnikov, Vitaly Kalashnikov, Conjectural variations equilibrium in a duopolyoly with a competitor maximizing domestic social surplus. Proceedings of the 2005 Internationalnal Applied Business Research Conference (IABR'2005), Puerto Vallarta, Mexico, March 14-18, 2005. -12 p.

[8] Kalashnikov, V.V.,Cordero, E., and Kalashnikov, V.V. -Jr., (2007). Stackelberg equilibrium in a mixed duopoly. - Proceedings of the 2 nd International Conference on Innovative Computing, Information and Control (ICICIC'2007), Kumamoto, Japan, September 05 - 07, 2007.

[9] Pal, D. (1998). Endogenous trimming in a mixed oligopoly. Economic Letters,61,pp.181-185. 